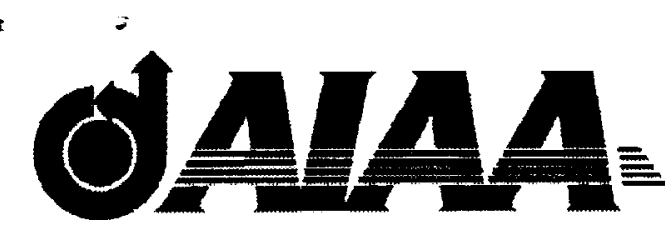

AIAA 2000-1560

Flight Control using Distributed

Shape-Change Effector Arrays

David L. Raney, Raymond C. Montgomery and Lawrence L .Green

NASA Langley Research Center

Hampton, VA 23681-2199

Michael A. Park

George Washington University

Joint Institute for the Advancement of Flight Sciences (JIAFS)

$41^{\text {st }}$ AIAA/ASME/ASCE/AHS/ASC Structures, Structural Dynamics, and Materials Conference \& Exhibit

3-6 April 2000

Atlanta, Georgia

For permission to copy or to republish, contact the American Institute of Aeronautics and Astronautics, 1801 Alexander Bell Drive, Suite 500, Reston, VA, 20191-4344. 


\title{
FLIGHT CONTROL USING DISTRIBUTED SHAPE-CHANGE EFFECTOR ARRAYS
}

\author{
David L. Raney*, Raymond C. Montgomery ${ }^{\dagger}$ and Lawrence L .Green ${ }^{*}$ \\ NASA Langley Research Center \\ Hampton, VA 23681-2199 \\ Michael A. Park \\ George Washington University \\ Joint Institute for the Advancement of Flight Sciences (JIAFS)
}

\begin{abstract}
Recent discoveries in material science and fluidics have been used to create a variety of novel effector devices that offer great potential to enable new approaches to aerospace vehicle flight control. Examples include small inflatable blisters, shape-memory alloy diaphragms, and piezoelectric patches that may be used to produce distortions or bumps on the surface of an airfoil to generate control moments. Small jets have also been used to produce a virtual shapechange through fluidic means by creating a recirculation bubble on the surface of an airfoil. An advanced aerospace vehicle might use distributed arrays of hundreds of such devices to generate moments for stabilization and maneuver control, either augmenting or replacing conventional ailerons, flaps or rudders. This research demonstrates the design and use of shape-change device arrays for a tailless aircraft in a low-rate maneuvering application. A methodology for assessing the control authority of the device arrays is described, and a suite of arrays is used in a dynamic simulation to illustrate allocation and deployment methodologies. Although the authority of the preliminary shape-change array designs studied in this paper appeared quite low, the simulation results indicate that the effector suite possessed sufficient authority to stabilize and maneuver the vehicle in mild turbulence.
\end{abstract}

\section{INTRODUCTION}

A number of concepts for novel control effector devices have recently been developed which offer great potential to enable entirely new approaches to aerospace vehicle flight control. Examples of such devices include small inflatable blisters, shape-memory alloy diaphragms and piezoelectric patches that may be used to produce distortions or bumps on the surface of an airfoil, as well as small piezoelectric pumps that can produce oscillatory surface jets. Potential applications of these devices include forebody vortex asymmetry management (Roos), control and manipulation of shear flows (Smith, Glezer), fluidic thrust vectoring (Pack), and low angle-of-attack lift augmentation (Nae). ${ }^{1-4}$ Pulsed blowing has also been used to actively vary the reattachment location of a separated flow over specifically designed portions of an airfoil (Seifert, Pack) ${ }^{5,6}$ The Aircraft Morphing Program under way at the NASA Langley Research Center focuses on the development and application of these novel effector devices, covering a spectrum research topics which include materials development, actuator design and testing, CFD modeling and optimization methods, dynamic simulation and control using such devices (McGowan). ${ }^{7}$ In this study we will examine the potential to use distributed arrays of shape-change devices to provide a basis for aircraft flight control. An advanced aerospace vehicle might use hundreds of small shape-change devices to generate forces and moments for stabilization and maneuver control, without the need for conventional, hydraulically actuated ailerons, flaps or rudders as investigated by Scott and Montgomery, and by Allan. ${ }^{8.9}$ Potential reasons to consider such alternatives include reduced observability, redundancy, and possible weight reduction of the overall effector complement.

\footnotetext{
" Research scientist, Dynamics and Control Branch, MS 132, Member AIAA.

† Research scientist, Dynamics and Control Branch, MS 132, Senior Member AIAA.

${ }^{\ddagger}$ Research scientist, Multidisciplinary Optimization Branch, MS 159, Senior Member AIAA.

Graduate Student, NASA Langley Research Center, Multidisciplinary Optimization Branch, MS 159, Member AIAA.
}

Copyright $\bigcirc 2000$ by the American Institute of Aeronautics, Inc. No copyright is asserted in the United States under Title 17, U.S. Code. The Government has royalty-free license to exercise all rights under the copyright claimed herein for govemment purposes. All other rights reserved by the copyright owner. 
Given this goal, how might the best locations for placement of such devices on the aircraft surface be determined, and how might the devices be used in a control system to actually maneuver and fly the vehicle? This research attempts to address such questions by applying arrays of a generic shape-change device to a representative aircraft configuration in a dynamic simulation. This work builds upon an initial investigation that was conducted by Scott and Montgomery ${ }^{8}$, extending the research to include an effector placement study followed by a revised effector suite, a new allocation and deployment method, and a new control design. The control system deploys distributed arrays of the shape-change devices in a "quantized" fashion. That is to say that each small bump in an array is either completely on or off, and more of them are turned on to produce larger forces as needed. Using these arrays, the control system is able to stabilize and maneuver the vehicle without conventional hinged surfaces such as ailerons or a rudder. The predicted authority of the designs studied in this paper is rather low when compared to conventional effectors, so the target for utilization of this technology is currently low-rate maneuvers (roll rates of 10 degrees per second or less).

\section{SUBJECT CONFIGURATION}

The example aircraft design used in this paper is the Innovative Control Effector (ICE) aircraft from Lockheed Martin Tactical Aircraft Systems, (Dorsett). ${ }^{10}$ The configuration is a tailless, delta-wing fighter, which was developed for the purpose of investigating novel control effector concepts and arrangements. NASA is using the ICE design, shown in Figure 1, as an example configuration under a cooperative agreement with Lockheed Martin.

\section{Wing Characteristics}

Area $\ldots . .75 .12 \mathrm{~m} 2$ (808.6 ft. $\left.{ }^{2}\right)$

Span .... $11.43 \mathrm{~m}(37.5 \mathrm{ft}$.)

Aspect Ration ... 1.74

Leading Edge Sweep .. 1.134 rad (65 deg.)
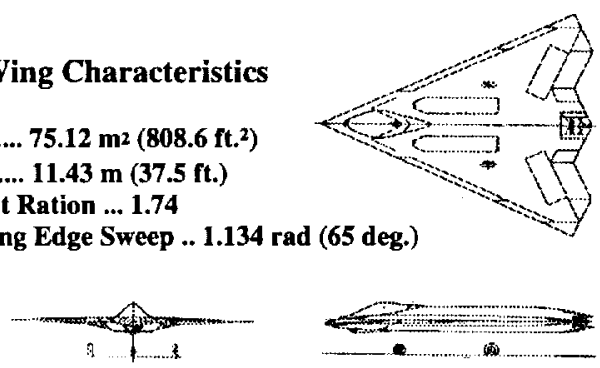

Figure 1. Lockheed-Martin's ICE configuration.

A simulation database of stability and control derivatives was obtained for this configuration from Lockheed Martin. The potential of shape change device arrays to serve as alternative control effectors for the ICE aircraft is examined using the simulation model with linearized aerodynamics. A low-speed, potential flow code (the Panel Method from Ames Research Center, PMARC) is used to predict the forces and moments that would be produced by the shape-change effector arrays which were designed for this configuration. "1

The analysis was performed for a flight condition of Mach 0.6 at an altitude of $15000 \mathrm{ft}$. The equilibrium trim angle-of-attack at this flight condition is approximately 4.4 degrees. Control moments required to trim at this flight condition are assumed to be generated by conventional effectors. The shape-change effector arrays are used to stabilize and maneuver the vehicle about this equilibrium flight condition. In this paper, the term "device" will be used to refer to an individual shape-change effector unit or single bump, the term "array" will refer to a particular grouping of adjacent devices, and the term "suite" will refer the entire collection of device arrays with which the vehicle is outfitted.

\section{CONTROL EFFECTOR DEVICE MODEL}

The generic shape-change device model used in this investigation consists of a small bump which deflects normal to the surface of the vehicle. The resulting shape-change was represented on a panel model of the ICE configuration by displacing a given gridpoint a prescribed distance, $X_{N}$, along a vector which is normal to the geometry surface, as shown in Figure 2. The perturbed geometry was then analyzed using the PMARC code, and the resulting forces and moments were differenced from the values for the nominal geometry to provide an estimate of the forces and moments that would be produced by the surface distortion. Several assumptions are implicit in this modeling approach, including the assumption that the surface distortion does not produce separated flow and the assumption that the flow is entirely subsonic. These restrictions were imposed by the potential flow code that was used to evaluate the shape-change devices.

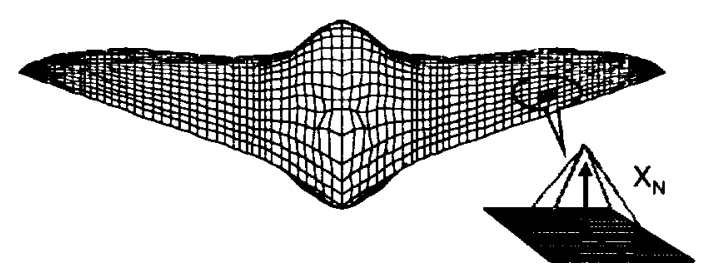

Figure 2. Shape-change device modeled as deflection of gridpoint along normal vector. 
The use of the modeling approach illustrated in Figure 2 appears reasonable for shapememory alloy diaphragms, piezoelectric domes and inflatable blisters which produce real surface distortions. The use of fluidic devices, such as pulsed jets and zero-net-mass-flow oscillatory jets ("synthetic jet"), to produce a virtual shapechange is far less understood and is a subject of current research. Kral and Donovan have performed a detailed study regarding the simulation of an isolated jet using Reynoldsaveraged Navier-Stokes (RANS) equations. ${ }^{12,13}$ Their result, shown in Figure 3, demonstrates the effect of a steady-jet on a NACA 0012 airfoil at $\mathrm{R}_{\mathrm{N}}=8.5 \times 10^{6}$ and $\alpha=.0698 \mathrm{rad}\left(4.0^{\circ}\right)$, The figure shows streamlines for the $\mathrm{U}_{\mathrm{i}} / \mathrm{U}_{\infty}=1.0$ case, illustrating that the effect of the steady jet is to produce a virtual distortion of the surface resulting from the generation of a small recirculation bubble, as well as an effluent added to the primary flow. A proper potential model would include a surface distortion as well as an effluent. In this paper we assume there is zeromass-transfer and therefore no added effluent.

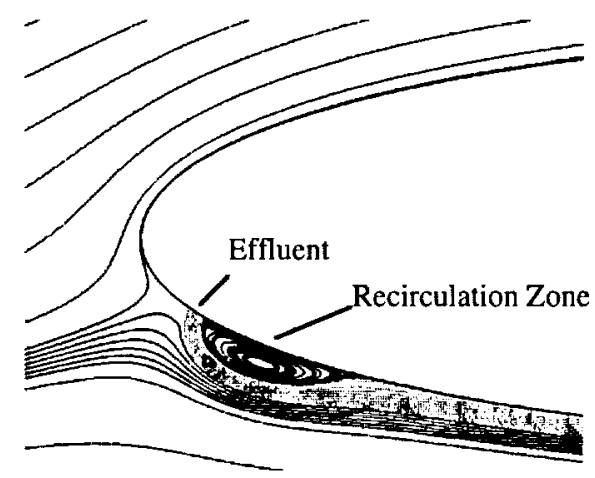

Figure 3. Streamlines $\alpha=.0698 \mathrm{rad}\left(4.0^{\circ}\right)$, with steady-jet control at $U_{j} U_{\infty}=1.0$.

The modeling approach described above includes no description of the actuator dynamics. A recent investigation by Pack found the response time of an exhaust flow to a thrustvectoring pulsed jet to be very fast -- on the order of $22 \mathrm{~ms}$, including both the actuation of the jet device itself and the fluidic response to the presence of the jet. ${ }^{3}$ Other means of generating the shape-change, such as inflatable blisters, could presumably be slower since the response time would clearly be dependent upon the particular mechanization employed. The goal of this investigation was to examine the issues of shape-change effector placement, deployment, and use in control design, rather than to develop a high-fidelity model of a shape-change effector, and so an instantaneous response of the device was deemed sufficient for this first-order model.

\section{DESIGN OF EFEECTOR ARRAYS}

A major issue to consider in the design of shape-change effector arrays is where to locate the devices on the aircraft surface for maximum benefit. A sensitivity analysis was performed using a geometry model of the ICE configuration to aid in determining where the device arrays should be positioned on the vehicle. The analysis involved differentiating the PMARC code using the "ADIFOR" tool (Automatic Differentiation of Fortran, Carle \& Fagan). ${ }^{14}$ The differentiated code was then applied to the ICE configuration model to produce the partial derivative of the forces and moments acting on the aircraft with respect to a displacement along the surface normal at every grid point on the aircraft geometry model, as described by Park \& Green. ${ }^{15}$ The resulting sensitivity database of pitch, roll, and yaw moment derivatives with respect to a normal displacement at every gridpoint on the geometry (taken individually) is shown as a set of shaded planform maps in Figure 4. The shaded regions in the figure indicate greater moment sensitivity and therefore suggest potential locations at which to place the shape-change devices. The sensitivity plots are described in much greater detail by Park \& Green. ${ }^{15}$

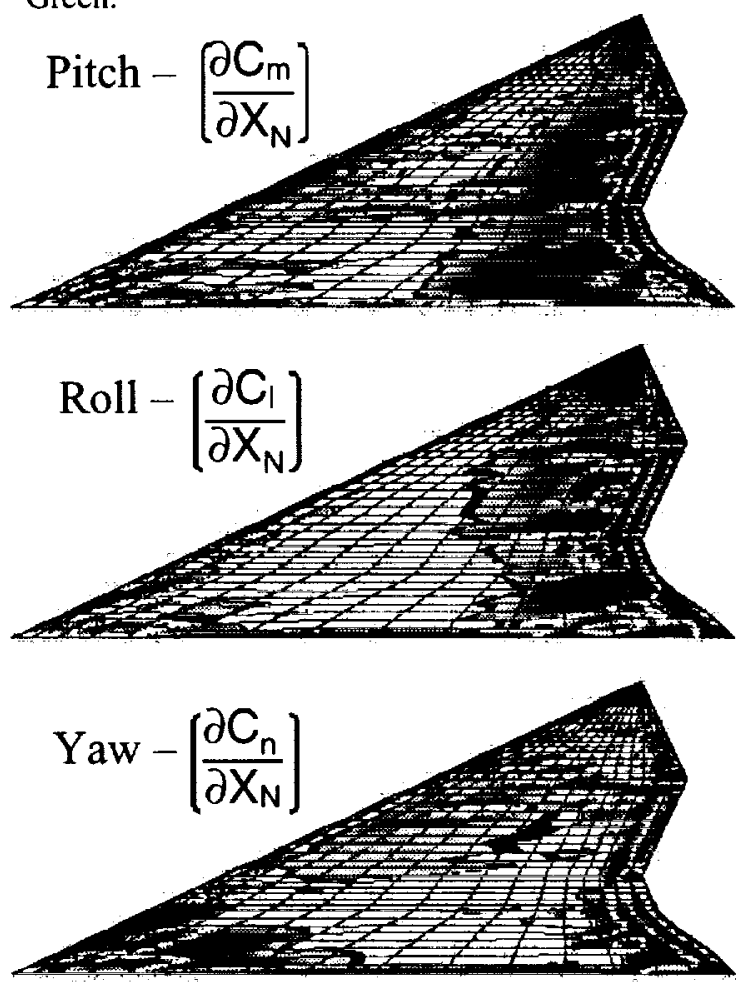

Figure 4. Moment sensitivity databases for gridpoint displacements produced by applying ADIFOR to PMARC using the ICE model. 
The databases shown in Figure 4 were incorporated into an interactive design tool that was developed to allow an engineer to quickly build up and analyze distributed arrays of small shape-change devices on the surface of the ICE aircraft. The tool was produced using Matlab ${ }^{T M}$, which provides basic constructs for generating the interactive graphical user interface and datamanipulation functions. It allows the designer to use the sensitivity data in a subjective fashion to guide the placement, size, and shape of the array so that it can produce the forces and moments required to maneuver the vehicle.

The graphical user interface for the effector array design tool is shown in Figure 5. Using this tool, the designer designates the geometry gridpoints at which to place each element of the shape-change array. The designer also defines a unit deflection magnitude for each element of the array. Once a grouping of shape-change devices has been defined, the designer can obtain a preliminary prediction of its effectiveness and generate a perturbed geometry grid that includes the deployed effector array. This geometry file can then be used with aerodynamic analysis programs, in this case the PMARC code, to further assess the effectiveness of the device. Although the design tool provides some subjective guidance regarding the location and shape of a given device array, it does not provide insight regarding the appropriate height profile (deflection magnitudes) for the various elements of the array. Such insight might be provided by a matrix of second derivatives of the control moment with regard to normal displacement of the geometry gridpoints (the Hessian). The ADIFOR automatic Fortran differentiation code has recently been endowed with a capability to generate the Hessian of the dependent parameters in a Fortran program by Carle and Fagan of Rice University, but this new capability has not yet been applied to the ICE shape-change sensitivity analysis.

The design tool was used to generate a series of 31 candidate effector array configurations. A plot of the pitch, roll, and yaw effectiveness for each of the arrays is shown in Figure 6. Candidate arrays were designed for various regions on the configuration, including upper and lower surface leading and trailing edges, mid-chord locations, and several wingtip positions.
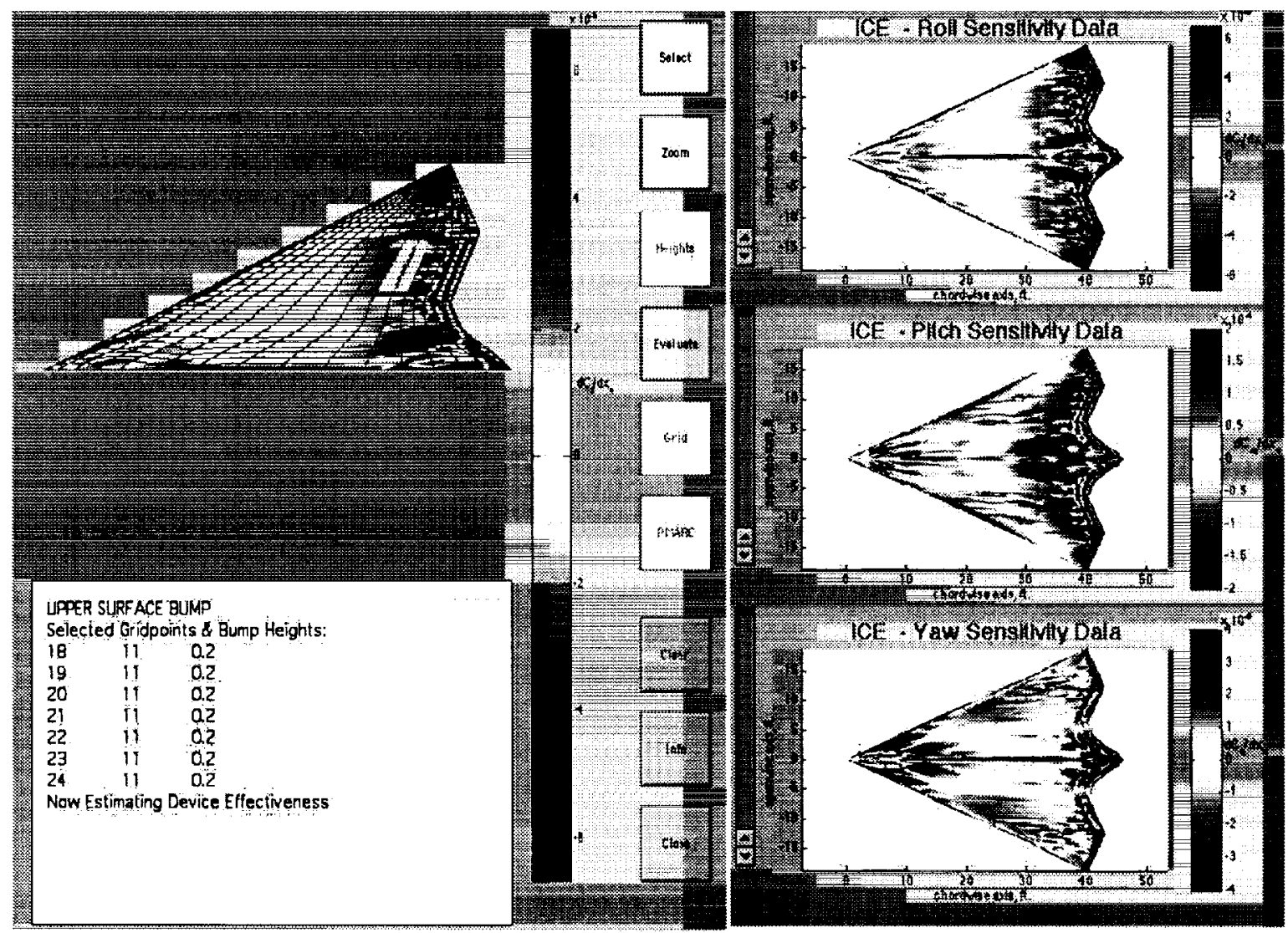

Figure 5. Shape-change effector array design tool graphical user interface. 


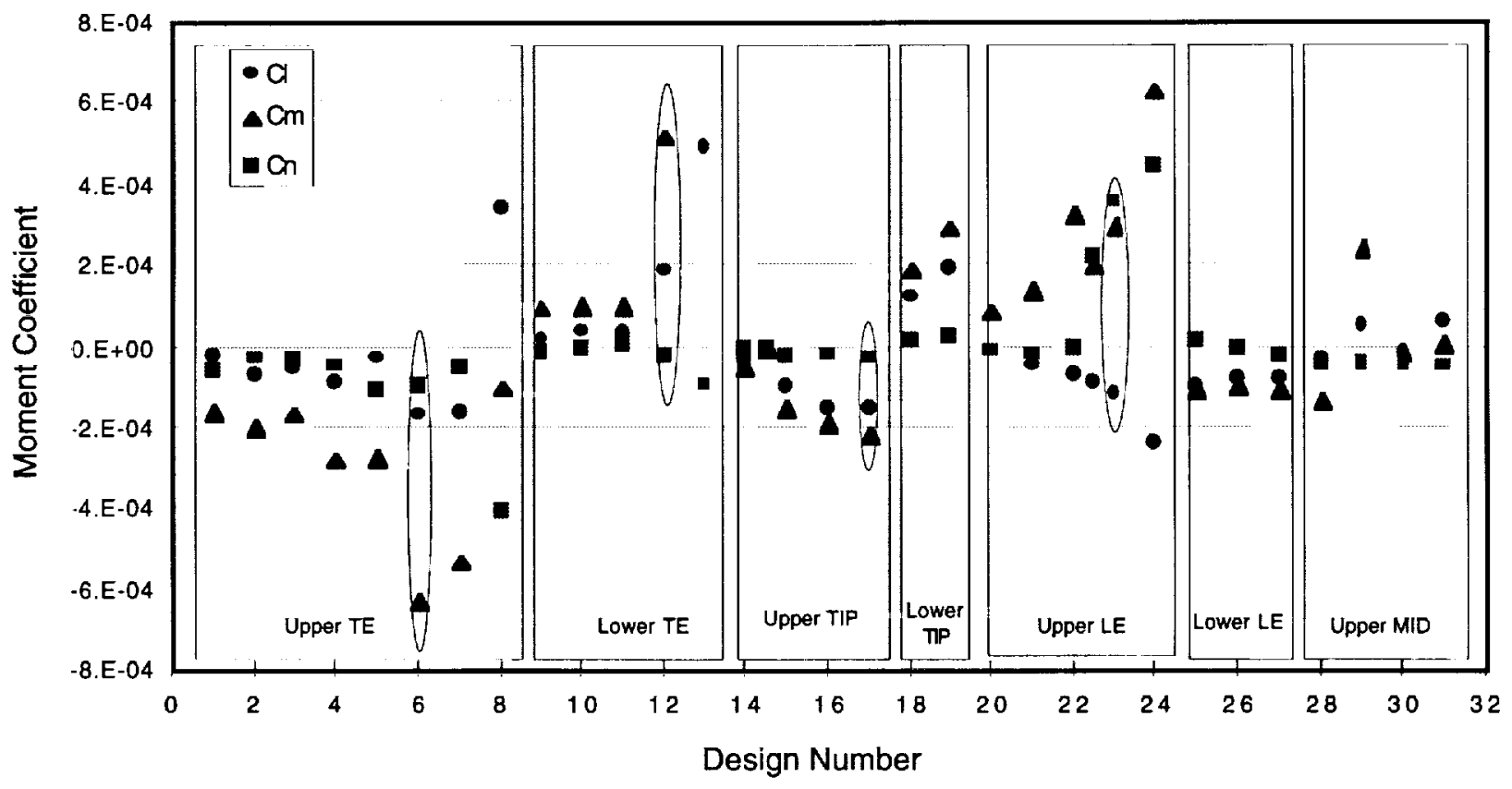

Figure 6. Control authority plots for 31 candidate shape-change effector array designs.

The candidate designs were evaluated on the basis of their authority and their ability to generate a relatively decoupled control moment. The total number of devices included in a given array was not considered as a factor in the evaluation. A particular combination of four device arrays was selected based on a subjective evaluation of suitability for providing 3 -axis moment control. The effectiveness derivatives corresponding to the selected array designs are circled in Figure 6. An ongoing investigation being performed in the Multidisciplinary Optimization Branch at the NASA Langley Research Center is examining the application of a more rigorous optimization method for the selection of an effector array suite from the candidate designs. ${ }^{16}$ The suite of four effector arrays that was selected for use in the remainder of this study is described below.

\section{SELECTED EEFECTOR ARRAYS AND DEPLOYMENT SCHEME}

The four distributed shape-change device arrays that were selected to compose the effector suite for the ICE configuration are shown in Figure 7. The effector suite includes four arrays on each wing, three on the upper surface and one on the lower surface. The entire suite of shape-change effector arrays includes a total of 156 individual devices, 78 per wing. The upper-surface leadingedge array (ULE) consists of 10 devices - one device at each of 10 span stations (chord lines) distributed along the leading edge as shown in Figure 7 . The lower-surface trailing-edge array (LTE) and upper-surface trailing-edge array (UTE) both consist of 22 devices - two adjacent devices at each of 11 span stations. The uppersurface wingtip array (UTip) consists of 24 devices - six adjacent devices at each of 4 span stations. The lower-surface trailing-edge, uppersurface trailing-edge, and upper-surface leadingedge arrays all have a maximum displacement height of 2.4 inches. The upper-surface wingtip array has a maximum displacement height of 1.2 inches.

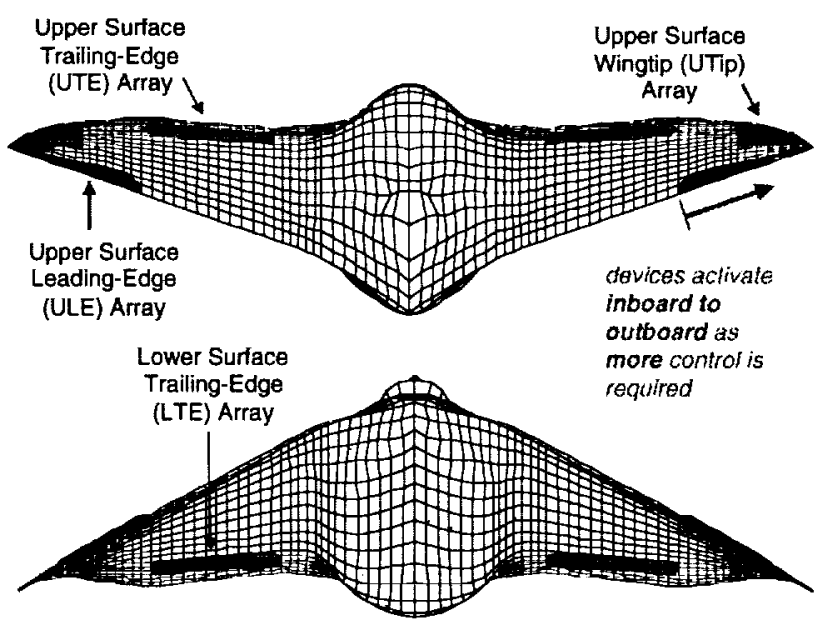

Figure 7. Selected shape-change effector array designs applied to ICE configuration. 
The effector suite was applied to the ICE vehicle in a simulation and used in a stability augmentation and control system design. The control system employs a "quantized spanwise" deployment scheme for activation of the device arrays, as noted in Figure 7 . That is to say that each device in an array is either completely on or off (rather than proportionally deployed), and more of them are turned on to produce larger forces as needed, from the most inboard to the most outboard span station of each array. All devices located along a particular span station in a given array operate together - turning on or off at the same time. This quantized deployment scheme addresses a realistic aspect of the control allocation problem, since a number of existing shape-change device concepts involve this sort of "bang-bang" operation.

Each of the four arrays were analyzed using PMARC in each of their quantized deployment states to generate a database of control effectiveness for use in a closed-loop dynamic simulation of the vehicle model. Figure 8 shows plots of the control effectiveness for the progressive spanwise deployment of each of the device arrays. The use of the PMARC predictions for control effectiveness in the dynamic simulation constitutes a quasi-static assumption since unsteady aerodynamic effects due to the transient deployment of the devices are neglected.

\section{DYNAMIC SIMULATION}

A six degree-of-freedom dynamics simulation was used to investigate the unaugmented and augmented aircraft dynamics. The body axis coordinate system shown in Figure 9 is used for the formulation of the equations of motion.

The longitudinal configuration aerodynamics are represented in the simulation as a linear expansion of the longitudinal aerodynamic force and moment coefficients in angle of attack, $\alpha$, and pitch rate, $q$, plus the force and moment contributions from the shape-change effector deflections, $\delta$, as in the method of Bryan. ${ }^{17}$ Thus, the longitudinal coefficients, $\mathrm{Cx}, \mathrm{Cz}$, and $\mathrm{Cm}$, are expressed as:

$$
\begin{aligned}
& \mathrm{Cx}=\mathrm{Cx}_{\mathrm{o}}+\mathrm{Cx}_{\alpha} \alpha+C \mathrm{x}_{\mathrm{q}} \mathrm{q}(\mathrm{c} / 2 \mathrm{~V})+\mathrm{Cx}_{\delta} \delta \\
& \mathrm{Cz}=\mathrm{Cz}_{\mathrm{o}}+\mathrm{Cz}_{\alpha} \alpha+\mathrm{Cz}_{\mathrm{q}} \mathrm{q}(\mathrm{c} / 2 \mathrm{~V})+\mathrm{Cz}_{\delta} \delta \\
& \mathrm{Cm}=\mathrm{Cm}_{\mathrm{o}}+\mathrm{Cm}_{\alpha} \alpha+\mathrm{Cm}_{\mathrm{q}} \mathrm{q}(\mathrm{c} / 2 \mathrm{~V})+\mathrm{Cm}_{\delta} \delta
\end{aligned}
$$
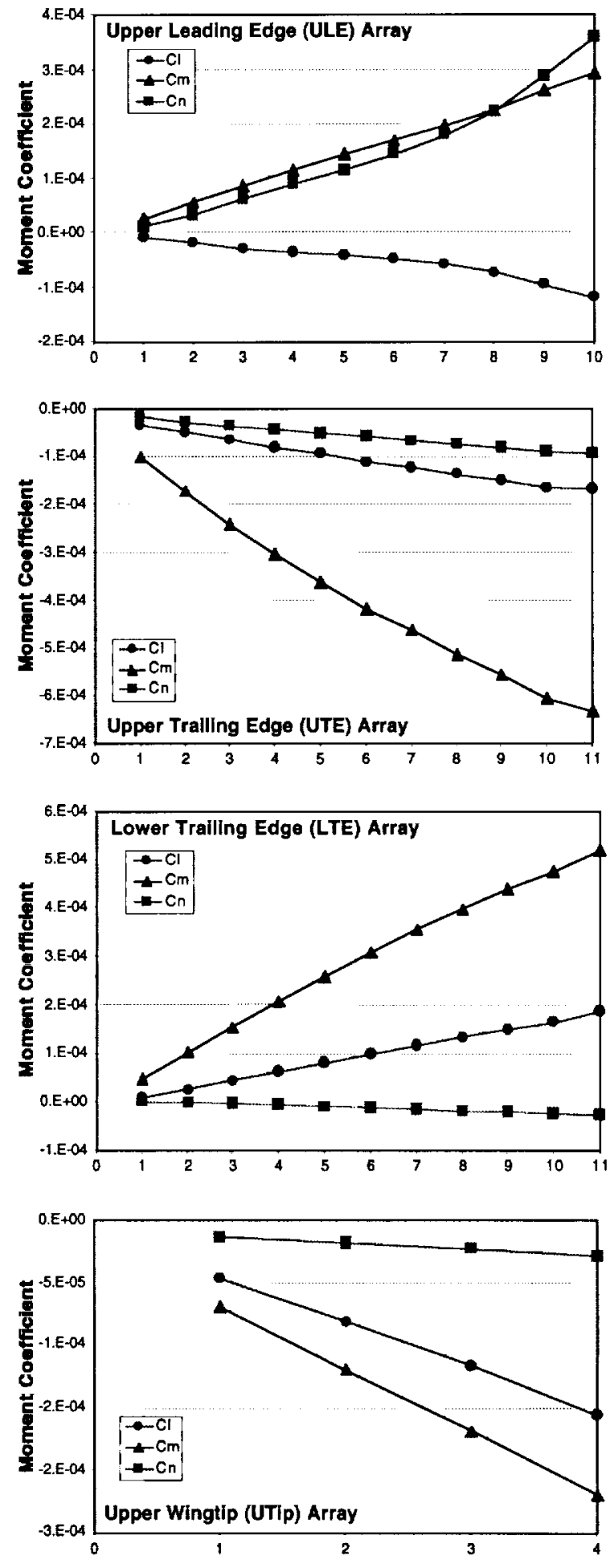

Number of Span Stations Activated

Figure 8. Control effectiveness buildup for each of 4 shape-change effector arrays included in ICE effector suite (right wing). 


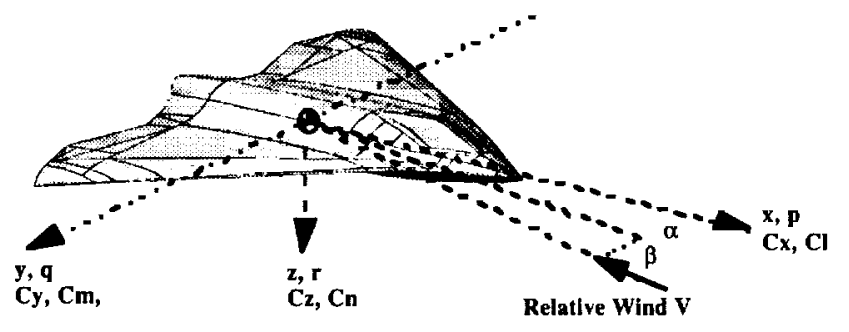

Figure 9. Body axis coordinate system definitions used in dynamic simulation.

Dependence on both angle of attack, $\alpha$, and angle of sideslip, $\beta$, is retained for the lateraldirectional force and moment calculation, so the coefficients, $\mathrm{Cy}, \mathrm{Cl}$, and $\mathrm{Cn}$, are expressed as:

$$
\begin{aligned}
& \mathrm{Cy}=\mathrm{Cy}_{\beta} \beta+\mathrm{Cy}_{\mathrm{p}} \mathrm{p}(\mathrm{b} / 2 \mathrm{~V})+\mathrm{Cy}_{\mathrm{r}} \mathrm{r}(\mathrm{b} / 2 \mathrm{~V})+\mathrm{Cy}_{\delta} \delta \\
& \mathrm{Cl}=\mathrm{Cl}_{\beta} \beta+\mathrm{Cl}_{\mathrm{p}} \mathrm{p}(\mathrm{b} / 2 \mathrm{~V})+\mathrm{Cl}_{\mathrm{r}} \mathrm{r}(\mathrm{b} / 2 \mathrm{~V})+\mathrm{Cl}_{\delta} \delta \\
& \mathrm{Cn}=\mathrm{Cn}_{\beta} \beta+\mathrm{Cn}_{\mathrm{p}} \mathrm{p}(\mathrm{b} / 2 \mathrm{~V})+\mathrm{Cn}_{\mathrm{r}} \mathrm{r}(\mathrm{b} / 2 \mathrm{~V})+\mathrm{Cn}_{\delta} \delta
\end{aligned}
$$

Where,

$$
\begin{aligned}
& \mathrm{Cy}_{\beta}=\mathrm{Cy}_{\beta \mathrm{o}}+\mathrm{Cy}_{\beta \alpha} \alpha \\
& \mathrm{Cl}_{\beta}=\mathrm{Cl}_{\beta \mathrm{o}}+\mathrm{Cl}_{\beta \alpha} \alpha \\
& \mathrm{Cn}_{\beta}=\mathrm{Cn}_{\beta o}+\mathrm{Cn}_{\beta \alpha} \alpha
\end{aligned}
$$

The parameters relating to flight condition, including total air speed, $\mathrm{V}$, and dynamic pressure, qbar, are calculated as:

$$
\begin{aligned}
& V=\left(u^{2}+v^{2}+w^{2}\right)^{1 / 2} \\
& q b a r=\rho \cdot V^{2} / 2 \\
& \alpha=\arctan (w / u) \\
& \beta=\arcsin (v / V)
\end{aligned}
$$

The geometry constants, $c, b$, and $S$ are the reference chord length, wing span, and wing area, respectively. Also $(\mathrm{u}, \mathrm{v}, \mathrm{w})$ and $(\mathrm{p}, \mathrm{q}, \mathrm{r})$ are the translational and rotational rates about the body-fixed, reference $(x, y, z)$ axes of the aircraft, respectively, and $(\mathrm{Cx}, \mathrm{Cy}, \mathrm{Cz})$ and $(\mathrm{Cl}, \mathrm{Cm}, \mathrm{Cn})$ are the aerodynamics force and moment coefficients about the $(x, y, z)$ axes, as indicated in Figure 9. The equations of motion for the rigid body dynamics of aircraft are well developed and available in texts (Etkin). ${ }^{18}$ They require a description of the attitude of the vehicle, which has traditionally been via Euler angles. These are used herein to represent the orientation of the aircraft with the sequence corresponding to $\psi$ about the $z$ the axis, $\theta$ about the $y$ axis, and $\phi$ about the $x$ axis. The kinematic differential equations implemented in the simulation are: $d \theta / d t=q \cdot \cos (\phi)-r \cdot \sin (\phi)$

$\mathrm{d} \psi / \mathrm{dt}=(\mathrm{q} \cdot \sin (\phi)+\mathrm{r} \cdot \cos (\phi)) / \cos (\theta)$

$\mathrm{d} \phi / \mathrm{dt}=\mathrm{d} \psi / \mathrm{dt} \cdot \sin (\theta)+\mathrm{p}$

$\mathrm{dh} / \mathrm{dt}=\mathrm{u} \cdot \sin (\theta)-\mathrm{w} \cdot \cos (\theta) \cos (\phi)-\mathrm{v} \cdot \cos (\theta) \sin (\phi)$

where $h$ is the altitude. For the longitudinal variables, the dynamic equations of motion used are:

$$
\begin{aligned}
& \mathrm{du} / \mathrm{dt}=\mathrm{v} \cdot \mathrm{r}-\mathrm{w} \cdot \mathrm{q}+\mathrm{g}[(\mathrm{T}+\mathrm{Cx} \cdot \mathrm{qbar} \cdot \mathrm{S}) / \mathrm{W}-\sin (\theta)] \\
& \mathrm{dw} / \mathrm{dt}=\mathrm{u} \cdot \mathrm{q}-\mathrm{v} \bullet \mathrm{p}+\mathrm{g}[\cos (\theta) \cos (\phi)+\mathrm{Cz} \cdot \mathrm{qbar} \cdot \mathrm{S} / \mathrm{W}] \\
& \mathrm{dq} / \mathrm{dt}=\left[\mathrm{Cm} \cdot \mathrm{qbar} \cdot \mathrm{S} \cdot \mathrm{c}+\left(\mathrm{I}_{\mathrm{z}}-\mathrm{I}_{\mathrm{x}}\right) \mathrm{r} \cdot \mathrm{p}+\left(\mathrm{r}^{2}-\mathrm{p}^{2}\right) \mathrm{I}_{\mathrm{xz}}-\mathrm{r} \cdot \mathrm{H}_{\mathrm{T}}\right] \mathrm{I}_{\mathrm{y}}
\end{aligned}
$$

where $\mathrm{g}$ is gravity. Due to inertia terms it is convenient to define the total rolling moment, $\mathrm{L}$, and yawing moment, $\mathrm{N}$, for the lateral equations of motion as:

$$
\begin{aligned}
& L=C l \bullet q b a r \cdot S \bullet b+\left(I_{y}-I_{z}\right) \bullet q \cdot r+p \bullet q \cdot I_{x z} \\
& N=C n \bullet q b a r \cdot S \bullet b+\left(I_{x}-I_{y}\right) \bullet q \bullet p-q \cdot r \cdot I_{x z}+q \cdot H_{T}
\end{aligned}
$$

where $T$ is the engine thrust, and $H_{T}$ is the moment of momentum about the $x$ axis of the engine rotors which are assumed to be aligned with the body $\mathrm{x}$ axis. Assuming symmetry with respect to the $x-z$ plane, $I_{x}, I_{y}, I_{z}$ are the moments of inertia about the $x, y, z$ axes and $I_{x z}$ is the relevant product of inertia about the $y$ axis. Thus, the lateral equations of motion are:

$$
\begin{aligned}
& \mathrm{dv} / \mathrm{dt}=\mathrm{w} \cdot \mathrm{p}-\mathrm{u} \bullet \mathrm{r}+\mathrm{g}(\mathrm{Cy} \cdot \mathrm{qbar} \cdot \mathrm{S} / \mathrm{W}+\cos (\theta) \sin (\phi)) \\
& \mathrm{dp} / \mathrm{dt}=\left(\mathrm{I}_{z} \cdot \mathrm{L}+\mathrm{I}_{\mathrm{xz}} \cdot \mathrm{N}\right) /\left(\mathrm{I}_{\mathrm{x}} \cdot \mathrm{I}_{\mathrm{z}}-\mathrm{I}_{\mathrm{xz}}{ }^{2}\right) \\
& \mathrm{dr} / \mathrm{dt}=\left(\mathrm{I}_{\mathrm{xz}} \cdot \mathrm{L}+\mathrm{I}_{\mathrm{x}} \cdot \mathrm{N}\right) /\left(\mathrm{I}_{\mathrm{x}} \cdot \mathrm{I}_{\mathrm{z}}-\mathrm{I}_{\mathrm{xz}}{ }^{2}\right)
\end{aligned}
$$

The geometry constants used in the simulation are $c=28.75 \mathrm{ft}$., $b=37.5 \mathrm{ft}$., and $\mathrm{S}=$ $808.6 \mathrm{ft}^{2}$, and the mass/inertia parameters are $\mathrm{W}$ $=32750 \mathrm{lbf}, \mathrm{I}_{\mathrm{x}}=35479$ slug $-\mathrm{ft}^{2}{ }^{2}, \mathrm{I}_{\mathrm{y}}=78451$ slug $\mathrm{ft}^{2}, \mathrm{I}_{\mathrm{z}}=110627$ slug-ft. ${ }^{2}$, and $\mathrm{I}_{\mathrm{xz}}=-525$ slug-ft ${ }^{2}$. The aerodynamic coefficients for the ICE configuration at the selected design flight condition of Mach 0.6 and $15000 \mathrm{ft}$ are listed in Tables 1 and 2.

Table 1. Longitudinal Aerodynamic Coefficients for the ICE simulation.

\begin{tabular}{cccc}
\hline & \multicolumn{3}{c}{ Subscript } \\
\cline { 2 - 4 } & 0 & $\alpha$ & $\mathrm{q}$ \\
\hline $\mathrm{Cx}$ & 0.0166 & -0.1973 & 0. \\
$\mathrm{Cz}$ & 0.0395 & -2.2475 & 0. \\
$\mathrm{Cm}$ & 0.0036 & -0.0467 & -.39516 \\
\hline
\end{tabular}


Table 2. Lateral Aerodynamic Coefficients for the ICE simulation.

\begin{tabular}{ccccc}
\hline & \multicolumn{4}{c}{ Subscript } \\
\cline { 2 - 5 } & $\beta \mathrm{o}$ & $\beta \alpha$ & $\mathrm{p}$ & $\mathrm{r}$ \\
\hline $\mathrm{Cy}$ & -0.0534 & 0.2331 & 0. & 0. \\
$\mathrm{Cl}$ & 0.0109 & -0.7846 & -.016 & .021368 \\
$\mathrm{Cn}$ & -0.0099 & -0.1215 & -.021789 & -.01 \\
\hline
\end{tabular}

\section{CONTROL DESIGN USING SHAPE- CHANGE EFFECTOR ARRAYS}

Eigenvalues for the uncontrolled flight dynamic modes of the ICE aircraft model were obtained from a linearization of the simulation about the equilibrium trim condition. Table 3 presents the mode designations, frequencies and damping values for the open-loop poles that are plotted as circles in Figure 10.

Table 3. Open-loop poles, frequencies and damping ratios for the linearized ICE simulation at Mach 0.6 and $15000 \mathrm{ft}$.

\begin{tabular}{|c|c|c|c|}
\hline Eigenvalue & $\begin{array}{c}\text { Damping } \\
\text { Ratio }\end{array}$ & $\begin{array}{l}\text { Freq. } \\
(\mathrm{rad} / \mathrm{s})\end{array}$ & Mode \\
\hline $\begin{array}{r}-8.20 \mathrm{e}-01 \pm \\
2.04 \mathrm{e}+00 \mathrm{i}\end{array}$ & $3.74 \mathrm{e}-01$ & $2.20 \mathrm{e}+00$ & $\begin{array}{l}\text { Short- } \\
\text { Period }\end{array}$ \\
\hline $\begin{array}{r}-1.46 \mathrm{e}-03 \pm \\
6.64 \mathrm{e}-02 \mathrm{i}\end{array}$ & $2.20 \mathrm{e}-02$ & $6.64 \mathrm{e}-02$ & Phugoid \\
\hline$-1.28 \mathrm{e}+00$ & $1.00 \mathrm{e}+00$ & $1.28 \mathrm{e}+00$ & Roll \\
\hline $\begin{array}{r}5.72 \mathrm{e}-01 \pm \\
7.71 \mathrm{e}-01 \mathrm{i}\end{array}$ & $-5.96 e-01$ & $9.60 \mathrm{e}-01$ & $\begin{array}{c}\text { Dutch- } \\
\text { Roll }\end{array}$ \\
\hline$-2.27 e-02$ & $1.00 \mathrm{e}+00$ & $2.27 \mathrm{e}-02$ & Spiral \\
\hline
\end{tabular}

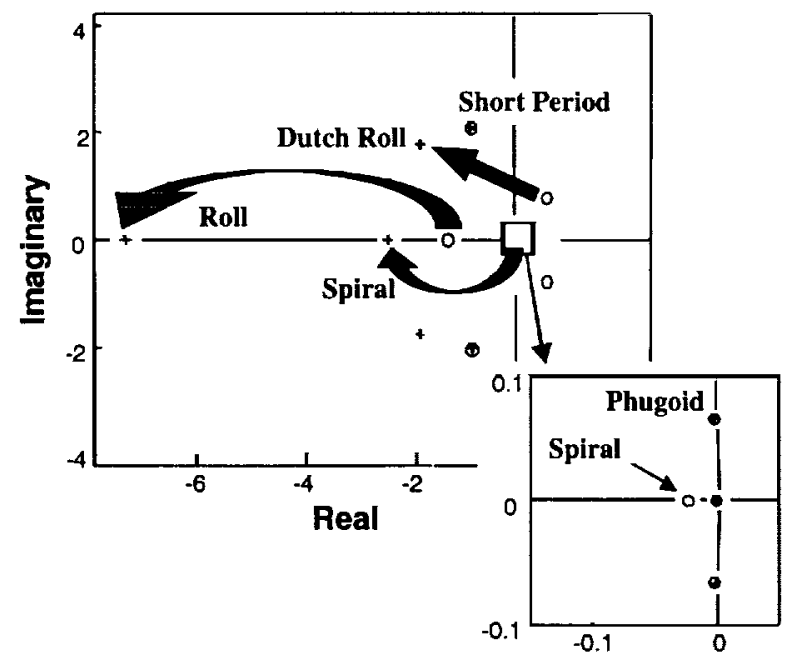

Figure 10. Open-loop and closed-loop pole locations for the ICE simulation.
The Iongitudinal phugoid and short period modes are stable, but the lateral Dutch-roll mode is not. The lateral instability is not unexpected due to the tailless configuration of the ICE aircraft.

A feedback control law was designed that uses the suite of shape-change device arrays to stabilize the vehicle's lateral dynamics while providing a bank-angle command tracking capability. To accomplish the design, it was necessary to develop a feedback architecture, associated filters and control gains, and to devise a control allocation method and deployment scheme for the suite of shape-change effector arrays. The controller stabilizes and maneuvers the vehicle using only the shape-change arrays, although the vehicle's steady-state trim is provided by conventional effectors.

A linear-systems pole-placement approach to the control law synthesis was selected for simplicity. Since the open-loop longitudinal dynamics are stable, the control design focuses on the augmentation of the lateral-directional dynamics. Therefore, only lateral dynamic states were used in the pole-placement controller. An overview of the dynamic simulation architecture showing the relation of the command generator, control law and allocator, is shown in Figure 11.

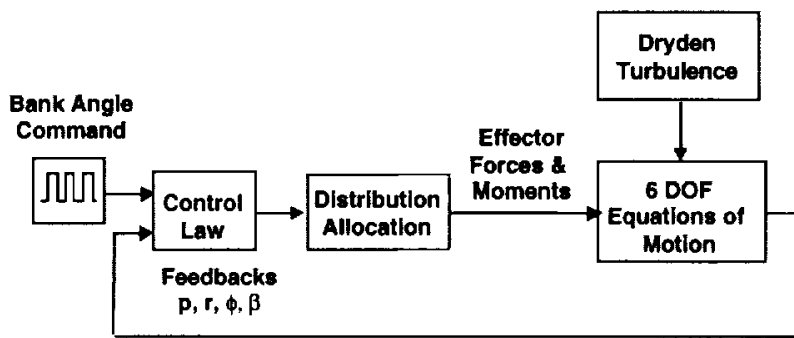

Figure 11. Block-diagram overview of simulation architecture.

The linearized lateral dynamics of the openloop aircraft model are represented in state-space form as:

$$
\dot{\mathrm{x}}=[\mathrm{A}] \mathrm{x}+[\mathrm{B}] \mathrm{u}
$$

where the transpose of the state vector, $x$, is given by:

$$
x^{T}=\{\beta \text { pr } \phi\}
$$

and the transpose of the control deflection vector, $\mathrm{u}$, is given by:

$$
\begin{array}{r}
\mathrm{u}^{\mathrm{T}}=\left\{\delta_{\text {UTER }} \delta_{\text {LTER }} \delta_{\text {ULER }} \delta_{\text {UTipR }} \cdots\right. \\
\left.\delta_{\text {UTEL }} \delta_{\text {LTEL }} \delta_{\text {ULEL }} \delta_{\text {UTTipL }}\right\}
\end{array}
$$


where each subscript corresponds to a particular effector array as defined in Figure 7, and the suffix $R$ or $L$ refers to the right or left wing, respectively. The matrices, $\mathrm{A}$ and $\mathrm{B}$, contain the aircraft stability coefficients and control coefficients, respectively, from the linear simulation model. To generate the closed-loop system we define a commanded input vector which drives the shape-change device arrays using the following control scheme:

$$
\mathrm{u}_{\mathrm{cmd}}=[\mathrm{P}] \mathrm{m}_{\mathrm{cmd}}
$$

The vector, $m_{c m d}$, represents the vector of desired roll, pitch, and yaw moments:

$$
\mathrm{m}_{\mathrm{cmd}}=\{\mathrm{ClCm} \mathrm{Cn}\}_{\mathrm{cmd}}^{\mathrm{T}}
$$

where $\mathrm{Cm}_{\mathrm{cmd}}=0$ and $\{\mathrm{Cl} \mathrm{Cn}\}_{\text {cmd }}$ is calculated by the following lateral-directional statefeedback control law:

$$
\{\mathrm{Cl} \mathrm{Cn}\}_{\text {cmd }}^{\mathrm{T}}=[\mathrm{K}] \mathrm{x}
$$

The feedback gain matrix, $\mathrm{K}$, is calculated using the pole-placement algorithm for linear systems as described by Franklin and Powell. ${ }^{19}$ The matrix, $P$, represents the control allocation function, which calculates a combined deployment of the eight effector arrays that will generate an approximation to the desired moment vector. In this design, the pseudoinverse allocation method is used, which is perhaps the most familiar and fundamental means of control allocation for coupled momentgenerating effectors. ${ }^{20}$ The pseudo-inverse matrix, $[\mathrm{P}]$, of the control effectiveness matrix is calculated as:

$$
\mathbf{P}=\mathbf{B}^{\mathrm{T}}\left[\mathrm{BB}^{\mathrm{T}}\right]^{-1}
$$

But since the shape-change effectors are one-sided, negative deployments of the devices are undefined. Therefore, negative deflections are reflected to the corresponding effector array on the opposite wing as positive deflections in the effector allocation algorithm. An error in pitch moment is generated by the reflection of negative asymmetric control deflections to the opposite wing. This effect is compensated by calculating an appropriate symmetric deflection of the upper or lower trailing edge arrays, depending upon the sign of the pitch moment error.

For the closed-loop system, the following desired lateral/directional pole locations were prescribed as targets for the pole-placement controller:

$$
\text { Despoles }=\left[\begin{array}{c}
-2.2500 \\
-7.2500 \\
-1.7678 \mathrm{e}+00+1.7678 \mathrm{e}+00 \mathrm{i} \\
-1.7678 \mathrm{e}+00-1.7678 \mathrm{e}+00 \mathrm{i}
\end{array}\right]
$$

These pole locations, shown as pluses on the plot in Figure 10, were selected to stabilize the vehicle's lateral dynamics and provide improved damping and settling time for gust response. For turn coordination, a washout filter is applied to the yaw-rate feedback with a transfer function that is given by:

$$
\frac{r_{\text {out }}}{r_{\text {in }}}=\frac{1.5 \mathrm{~s}}{1.5 \mathrm{~s}+1}
$$

A final provision for the use of the effector arrays is the presence of limiters within the control law, with limits that are dictated by the low authority of the control effector arrays. The derivative, Cnp, generates an adverse yawing moment in proportion to roll rate, tending to produce an undesired sideslip transient during rolling maneuvers. Additionally, as the vehicle rolls about the body axis, angle of attack is converted into sideslip. Feedback paths in the control law are provided to counteract these effects so as to generate coordinated turns. But due to the limited yaw authority of the effector suite, the ability of the control system to reject these effects is minimal, and maintaining turn coordination while rolling becomes the limiting factor in our achievable roll-rate command. Therefore, a roll-rate limiter was placed in the bank-angle command path. Iterative simulation runs which examined various values for the rollrate limit have revealed that a maximum limit of 10 degrees per second will prevent loss of control during rolling maneuvers, so this value was used as the maximum roll rate that could be commanded.

\section{SIMULATION RESULTS}

The effectiveness and utility of the shapechange effector array suite was evaluated by subjecting the dynamic simulation to various atmospheric disturbance levels and by assessing the maneuver capability that it provided. Using the shape-change arrays, the control system was able to stabilize and maneuver the vehicle without conventional control surfaces. The predicted authority of the shape-change arrays is rather low when compared to a rudder or aileron, so the control system generates relatively lowrate maneuvers. Figure 12 presents two time histories produced by the dynamic simulation in 
response to a \pm 20 -degree bank angle doublet command with and without mild Dryden-spectra turbulence $(\sigma=3 \mathrm{ft} / \mathrm{s})$.
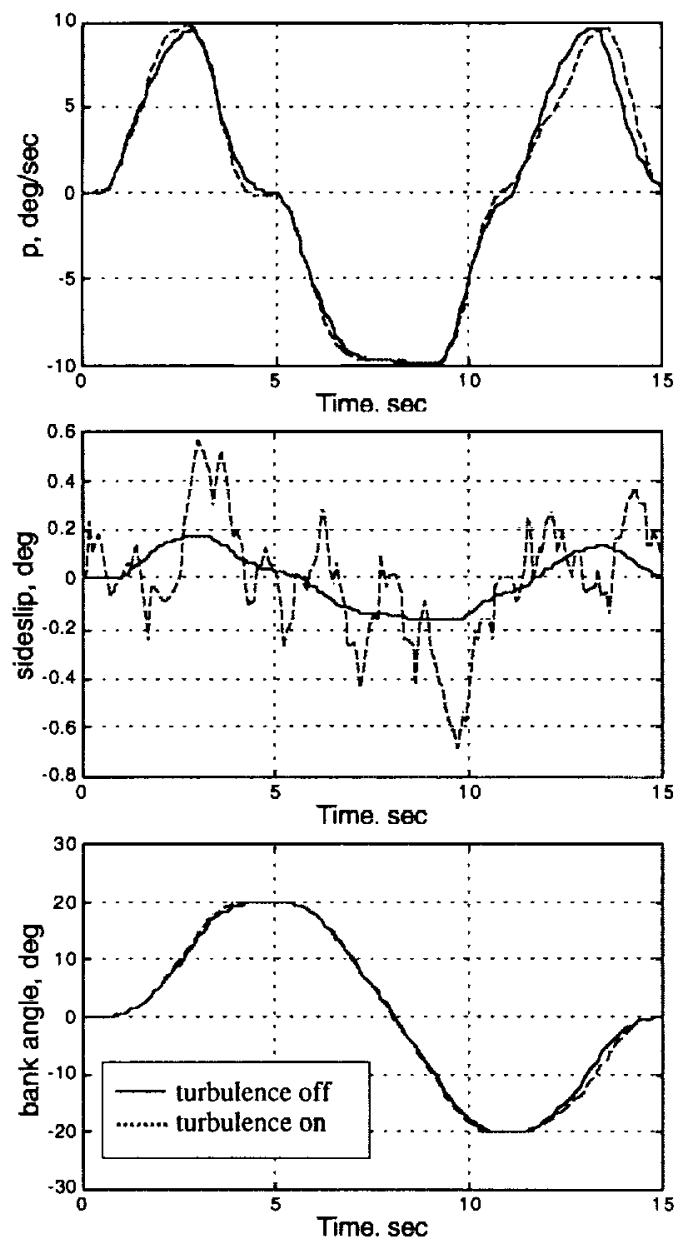

Figure 12. Simulation time histories in response to a 20-degree bank angle doublet command with and without mild turbulence.

The maximum roll-rate achieved is $10 \mathrm{deg} / \mathrm{s}$ due to the presence of the limiters in the command and feedback paths. Sideslip perturbations occur during the execution of the roll doublet. Larger sideslip transients result from the turbulence, but the bank-angle command time history is minimally impacted. In spite of the relatively low authority of the shape-change effector array suite, the control law is able to stabilize and maneuver the vehicle within the prescribed roll-rate limits.

Figure 13 shows a comparison of control effector array deployment with and without the Dryden turbulence. The vertical axis on the plots represents the number of devices that were activated in each of the eight arrays at any given time during the maneuver. The figure is not intended to convey specific details regarding any one particular array, but rather provides a general indication of the level of control activity and saturation that occurred during the run.
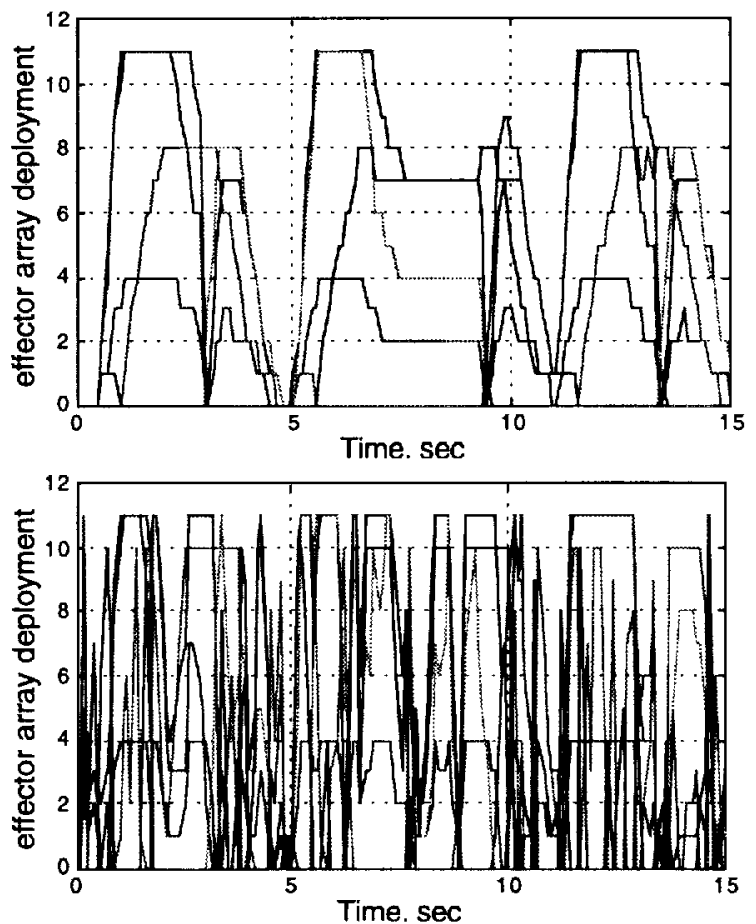

Figure 13. Shape-change effector array deployment time histories in response to a 20 degree bank angle doublet command with and without mild turbulence.

In both cases, various arrays in the control effector suite saturate, that is to say that all elements of a given array are turned on, for much of the time history. A higher degree of control activity and transient saturation results when mild turbulence is present, but the control system is still able to stabilize the lateral dynamics and perform the roll doublet. However, when the Dryden turbulence level was increased to moderate $(\sigma=6 \mathrm{ft} / \mathrm{s})$, the simulation diverged. The moderate turbulence field introduced perturbations from the trim condition which the effector suite did not have sufficient authority to reject, as deployed by the pole-placement control law design.

Time histories produced by the dynamic simulation in response to increasing crosswind gusts are shown in Figure 14. The vehicle is able to recover from crosswind gusts of up to 28 $\mathrm{ft} / \mathrm{s}$, but beyond that the effector suite lacks sufficient yaw authority to recover from the 
disturbance. This magnitude of crosswind gust equates to a sideslip angle of approximately 2.5 degrees at the simulation flight condition of Mach 0.6 and $15000 \mathrm{ft}$. The figure shows the response to increasing crosswind gust magnitudes in $5 \mathrm{ft} / \mathrm{s}$ increments, with the $30 \mathrm{ft} / \mathrm{s}$ crosswind gust resulting in a loss of control.
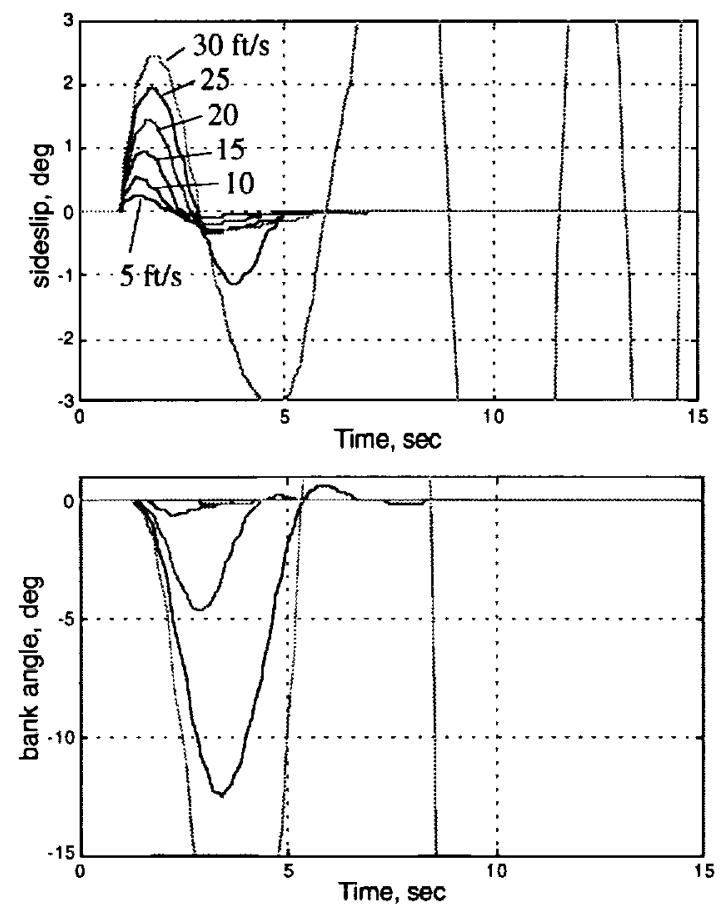

Figure 14. Simulation time histories in response to increasing magnitudes of crosswind gust ( 5 , $10,15,20,25$, and $30 \mathrm{ft} / \mathrm{s}$ ).

So the shape-change effector array suite examined in this report is of limited practicality in the regard that it provides relatively low disturbance-rejection capability. Although the effector suite appears suitable to stabilize the lateral-directional dynamics in the presence of mild turbulence, and to perform relatively lowrate rolling maneuvers, the effector suite lacks sufficient authority to act as the sole means of controlling the vehicle in all situations. Rather, such a complement of shape-change effector arrays may be use to augment conventional devices, potentially providing a low-observable flight mode that may be flown through an autopilot executing only low-rate maneuvers. They may also be used to provide a certain degree of control redundancy, reconfigurability or damage tolerance as an augmentation to a conventional effector complement. There is also potential for new novel effector concepts to be developed that offer much greater authority through separation control, forebody vortex manipulation, or other means, and in such cases additional control schemes for employing these devices in the portions of the flight regime at which they are most useful will need to be devised.

\section{CONCLUDING REMARKS}

This investigation has examined the use of distributed shape-change effector arrays in a flight control system for an example aircraft design. The subject aircraft was LockheedMartin's Innovative Control Effector (ICE) configuration. The distributed shape-change effector arrays were modeled as a series of bumps normal to the aircraft surface which could be deployed to generate control moments.

A sensitivity analysis was performed which provided insight regarding favorable locations for the placement of the shape-change device arrays on the ICE geometry. These sensitivity data were incorporated into an interactive shapechange array design tool, and a suite of arrays was developed and used in a lateral-directional control law design to illustrate allocation and deployment methodologies. A "quantized spanwise" deployment scheme was devised for activation of the device arrays. That is to say that each device in an array was either completely on or off (rather than proportionally deployed), and more of them were turned on to produce larger forces as needed, from the most inboard to the most outboard span station of each array.

The control design was used in a dynamic simulation of the ICE aircraft for a flight condition of Mach 0.6 at $15,000 \mathrm{ft}$. Though the authority of the particular device arrays that were designed in this investigation was quite low, the simulation results indicate that the effector suite possessed sufficient authority to stabilize and maneuver the example vehicle model, executing relatively low-rate rolling maneuvers at $10 \mathrm{deg} / \mathrm{s}$. When substantial atmospheric disturbances were included in the simulation (turbulence levels of 6 $\mathrm{ft} / \mathrm{sec}$ or cross wind gusts of $>28 \mathrm{ft} / \mathrm{sec}$ ), the device arrays did not possess sufficient authority to maintain stability of the vehicle's lateraldirectional dynamics using the control law presented in this report.

The shape-change device arrays studied in this investigation present a promising alternative for use in aircraft flight control. However, it is clear that experimental demonstrations of their application and further development of their 
control authority would bolster their case. Future research will focus on experimental validation of the predicted authority of various flow control devices and on flight control using large arrays of interacting effector devices. A broader database that will characterize the variation of control authority of the shapechange device arrays with angle of attack and Mach number is also planned.

\section{REFERENCES}

I Roos, Frederick W., McDonnell Douglas Corporation: "Synthetic-Jet Microblowing for Vortex Asymmetry Management on a Hemisphere-Cylinder Forebody", $28^{\text {th }}$ AIAA Fluid Dynamics Conference, paper AIAA 97-1973, Jun 29 - July2, 1997.

${ }^{2}$ Smith, B. L.; Glezer, A.: "Vectoring and SmallScale Motions Effected in Free Shear Flows using Synthetic Jet Actuators", $35^{\text {th }}$ Aerospace Sciences Meeting \& Exhibit, AIAA Paper 97-0213, January 1997.

${ }^{3}$ Pack, L. G.; Seifert, A.: "Periodic Excitation for Jet Vectoring and Enhanced Spreading", $37^{\text {th }}$ AIAA Aerospace Sciences Meeting and Exhibit, AIAA Paper 99-0672, January, 1999.

${ }^{4}$ Nae, C.: "Synthetic Jet Influence on NACA 0012 Airfoil at High Angles of Attack", AIAA Paper 98-4523.

${ }^{5}$ Seifert, A.; Darabi, A.; Wygnanski, I.: "Delay of Airfoil Stall by Periodic Excitation", Journal of Aircraft, Vol. 32, No. 4, JulyAugust, 1996.

${ }^{6}$ Seifert, A.; Pack, L.: "Oscillatory Control of Separation at high Reynolds Numbers", AIAA Paper 98-0214, Aerospace Sciences Meeting and Exhibit, 1998.

7 McGowan, A. R.; Horta, L. G.; Harrison, J. S.; Raney, D. L.: "Research Activities within NASA's Morphing Program", NATO RTO meeting - Applied Vehicle Technology Panel, October 1999, Ottawa, Canada.

${ }^{8}$ Scott, M., Montgomery, R., and Weston, R.: "Subsonic Maneuvering Effectiveness of High Performance Aircraft Which Employ Quasi-Static Shape Change Devices", SPIE 1998 International Symposium on Smart Structures and Materials, paper 3326-24, pp. 223-233.
9 Allan, B.; Holt, M., Packard, A.: "Simulation of a Controlled Airfoil with Jets", NASA CR-201750; ICASE Report No. 97-55, October 1997.

10 Dorsett, K. M. and D.R. Mehl, 1996. "Innovative Control Effectors (ICE)", Wright Laboratory Report, WL-TR-963043, January 1996.

II Ashby, D., Dudley, M., Iguchi, S., Browne, L., and Katz, J.: "Potential Flow Theory and Operation Guide for the Panel Code PMARC_12", NASA Ames Research Center, Moffett Field, CA, Dec. 1992.

12 Kral, L., Dononvan, J. Cain, B, Cary, A.: "Numerical Simulation of Synthetic Jet Actuators", AIAA paper 97-1824.

13 Donovan, J.F., L.D. Kral, and A.W. Cary: "Active Flow Control Applied to an Airfoil", 36th AIAA Aerospace Sciences Meeting, paper AIAA 98-0210, Jan. 1998.

14 Carle, A., Fagan, M., and Green, L.: "Preliminary Results from the Application of Automated Adjoint Code Generation to CFL3D", AIAA Paper 98-48078, Sept. 1998.

15 Park, M., Green, L., Montgomery, R., Raney, D.: "Determination of Stability and Control Derivatives using Computational Fluid Dynamics and Automatic Differentiation", AIAA Paper 99-3136, June 1999.

${ }^{16}$ Padula, S. L.; Rogers, J. L.; Raney, D. L.: "Multidisciplinary Techniques and Novel Aircraft Control Systems", pending $8^{\text {th }}$ AIAA/NASA/USAF/ISSMO Multidisciplinary Analysis and Optimization Symposium, September 6-8, 2000.

17 G. H. Bryan, "Stability in Aviation", Macmillan Co., London, 1911.

18 B. Etkin, "Dynamics of Flight - Stability and Control", John Wiley and Sons, Inc., New York, 1959.

${ }^{19}$ G. F. Franklin; J. D. Powell; A. E. Naeini: "Feedback Control of Dynamic Systems", Addison-Wesley Publishing Company, Inc., 1986.

20 Bordignon, K. A.; Durham, Wayne C.: "Closed-Form Solutions to Constrained Control Allocation Problem", Journal of Guidance, Control, and Dynamics, Vol. 18, No. 5, September-October 1995. 